\title{
Seeding of Single-Crystal Superalloys-Role of Constitutional Undercooling and Primary Dendrite Orientation on Stray-Grain Nucleation and Growth
}

\begin{abstract}
N. D'SOUZA, P.A. JENNINGS, X.L. YANG, H.B. DONG, P.D. LEE, and M. McLEAN
An experimental study, together with a two-dimensional numerical simulation of solute segregation, was conducted to investigate (1) the mechanism for stray-grain nucleation following seed melt-back and initial withdrawal and (2) the role of the primary dendrite disposition of the seed crystal in relation to the mold wall during growth. It is proposed that the factors contributing to stray-grain nucleation during initial withdrawal are (1) the magnitude of local, solute-adjusted undercooling and (2) the rapidly changing curvature of the solidification front close to the mold walls during the initial solidification transient. Based upon the calculated local undercooling and experimentally observed stray-grain morphologies, it was concluded that stray grains nucleate near the mold wall around the seed perimeter and behind the columnar dendrites that advance into the bulk liquid ahead of the melt-back zone. These grains then compete during growth with the dendrites originating from the seed. Therefore, the morphological constraints arising from the inclination of the primary dendrites from the seed crystal with respect to the mold wall (converging/diverging/axial $<001>$ ) determines the probability of the stray-grain nuclei developing into equiaxed/columnar grains following competitive growth.
\end{abstract}

\section{INTRODUCTION}

SINGLE-CRYSTAL turbine blades are routinely cast from Ni-based superalloys. The primary aims of producing single crystals are to (1) eliminate grain boundaries that limit creep ductility and (2) orient the elastically soft $<001>$ orientation parallel to the maximum load direction to minimize cyclic stresses during thermal cycling. ${ }^{[1]}$

However, in certain circumstances pertaining to mechanical response, it is necessary to impose a specific nonaxial $<001>$ orientation on the component. This is achieved using a single-crystal seed of desired orientation.

In commercial production, the prefabricated seed is partially melted-back during the soak period of the mold and, subsequently, molten alloy is introduced through the mold cavity across the seed melt-back interface and the mold is then withdrawn from the furnace. During directional solidification, it has been observed that there is a continuous nucleation of crystals with random orientations at the seed periphery, up to a distance of $\approx 2 \mathrm{~mm}$ ahead of the meltback interface. ${ }^{[2]}$ In current practice, these stray grains have to be eliminated using a spiral grain selector to transfer the desired single-crystal structure from the seed to the component. In order to remove the spiral selector during singlecrystal seeding, it is essential to understand the mechanism(s) by which these stray grains nucleate and to suppress their occurrence.

N. D'SOUZA, Casting Specialist, is with the Precision Casting Facility, Rolls-Royce plc, Derby DE24 8BJ, United Kingdom. P.A. JENNINGS, Casting Specialist, is with the Company Research and Development Foundry, Rolls-Royce plc, Filton, Bristol BS34 7QE, United Kingdom. X.L. YANG, Postgraduate Student, P.D. LEE, Reader, and M. McLEAN, Professor, are with the Department of Materials, Imperial College London, London SW7 2BP, UK. Contact e-mail: p.d.lee@imperial.ac.uk H.B. DONG, Lecturer, is with the Department of Engineering, University of Leicester, Leicester LE1 7RH, United Kingdom.

Manuscript submitted November 24, 2004.
One of the mechanisms proposed in a prior study was that secondary dendrites were pinched off by convective currents in the semisolid region of the melted-back seed and, subsequently, transported ahead of the dendrite tips to form these stray grains ${ }^{[3]}$ However, a more recent study discounted this theory using detailed optical and electron microscopy on quenched samples to capture the melt-back interface and the overlying liquid. ${ }^{[4]}$ Although islands of misoriented grains were observed to occur uniformly throughout the mushy zone and were attributed to melted-back secondaries, their density was insufficient to account for the concentration of defects observed at the periphery of the casting after withdrawal had started. Further, buoyancy-driven convective jets would drive the dendrite fragments to the interior, rather then the periphery. ${ }^{[5]}$

A subsequent investigation aimed at determining the origin and growth of these stray grains involved sequential microstructural characterizations beginning from the seed melt-back to $\approx 30 \mathrm{~mm}$ ahead of the growth front using optical and electron microscopy in conjunction with electron backscattered diffraction. ${ }^{[2]}$ The main observation was the profuse nucleation of equiaxed stray grains almost uniformly around the perimeter of the seed (Figure 1(a)) within a distance of $\approx 2 \mathrm{~mm}$ from the melt-back interface. This indicated that the nucleation of these stray grains could be a transient process caused by the thermal fluctuations during melt-back/startup. However, successive transverse sections moving away from the melt-back revealed that few of these grains survived, indicating that growth mechanisms also play a significant role (Figures 1(b) and (c)). It was concluded from these observations that the unwanted macroscopic stray grains are a manifestation of growth rather than of preferential nucleation.

The objective of the study described in this article is to understand the possible mechanisms of stray-grain nucleation and growth occurring during seed melt-back during directional solidification. In particular, the roles of both the 


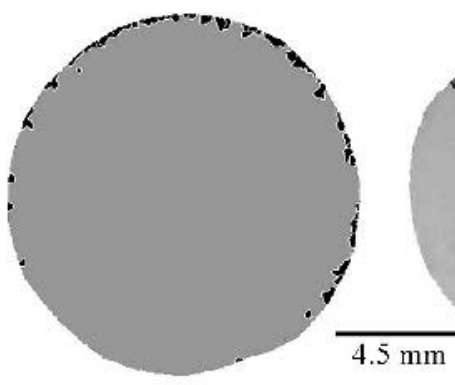

(a)

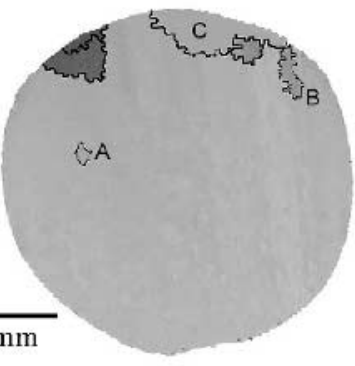

(b)

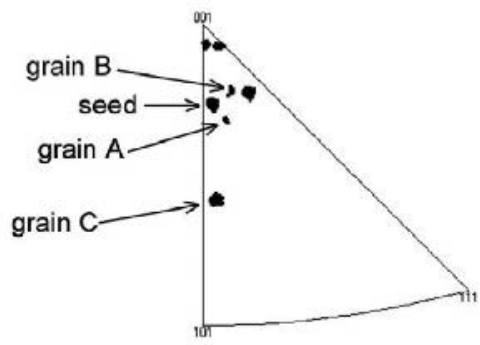

(c)

Fig. 1-(a) Electron backscattered diffraction analysis of a transverse section $\sim 2 \mathrm{~mm}$ ahead of the melt-back interface. $(b)$ Electron backscattered diffraction analysis of a transverse section well ahead of the melt-back interface, illustrating that only a few of the stray grains have survived after competitive growth. (c) An inverse pole figure of the grain orientations from (b) relative to the casting direction (based on Ref. 2).

initial thermal transient and seed orientation were investigated both via experiment and simulation.

Since nucleation and growth are distinct sequential phenomena, we consider these two aspects separately:

(1) A mechanism that can account for the profuse nucleation of stray grains, as observed in the analyses of Stanford et $a l .,{ }^{[2]}$ is identified through controlled experiments as well as through numerical simulations.

(2) The competitive growth of nucleated grains and primary dendrites with respect to (a) seed/mold heater configuration, which determines the local isotherms and (b) seeds with converging/diverging/axial $<001>$ in relation to the mold wall, determined by the primary dendrite orientation.

\section{EXPERIMENTAL INVESTIGATION}

It was concluded from prior experimental observations that the unwanted macroscopic stray grains are a manifestation of growth rather than of preferential nucleation. In the present work, the experiments and simulations conducted concentrated on the competitive growth between the seed and the stray grains nucleated at the perimeter of the seed, in particular, the influence of (1) the asymmetric thermal conditions in the furnace leading to possible curvature of the local liquidus isotherm and (2) the seed orientation relative to the casting geometry. In this section, experimental results on the growth of stray grains in castings with different thermal geometries and seed orientations are reported.

\section{A. Details of Casting Procedure}

A fully instrumented, industrial directional solidificationcasting furnace situated at Rolls-Royce Company Research and Development Foundry (Bristol, United Kingdom) was used for the present investigation. A complete description of the furnace is available elsewhere, ${ }^{[6,7]}$ and only the salient features will be highlighted here. The furnace is comprised of three zones: (1) a vacuum induction melting unit, (2) a resistance-heated central chamber, and (3) a withdrawal chamber (Figure 2). The basic steps during casting of singlecrystal seeded components are as follows.

(1) All three chambers are evacuated to a partial pressure of $\approx 10^{-3} \mathrm{~Pa}$, and the mold containing the seeds of

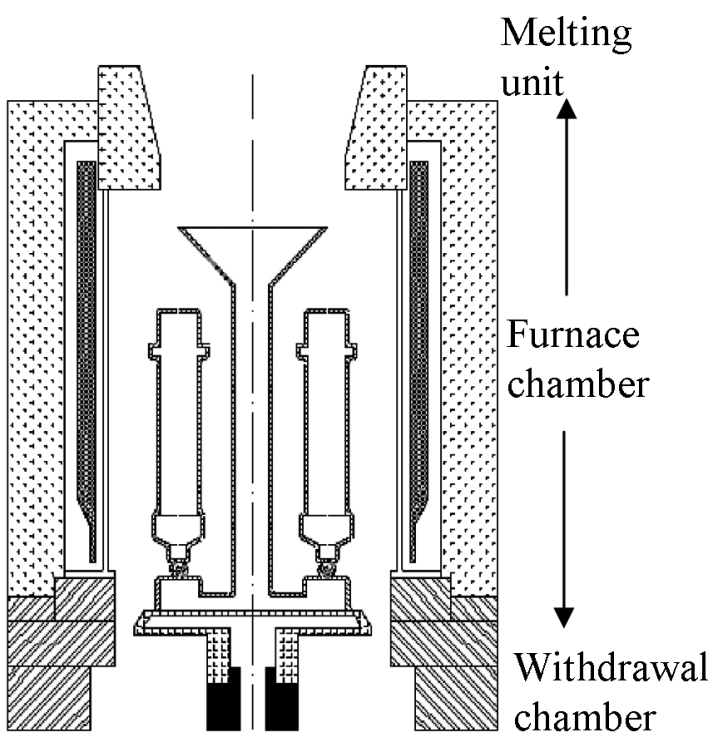

(a)

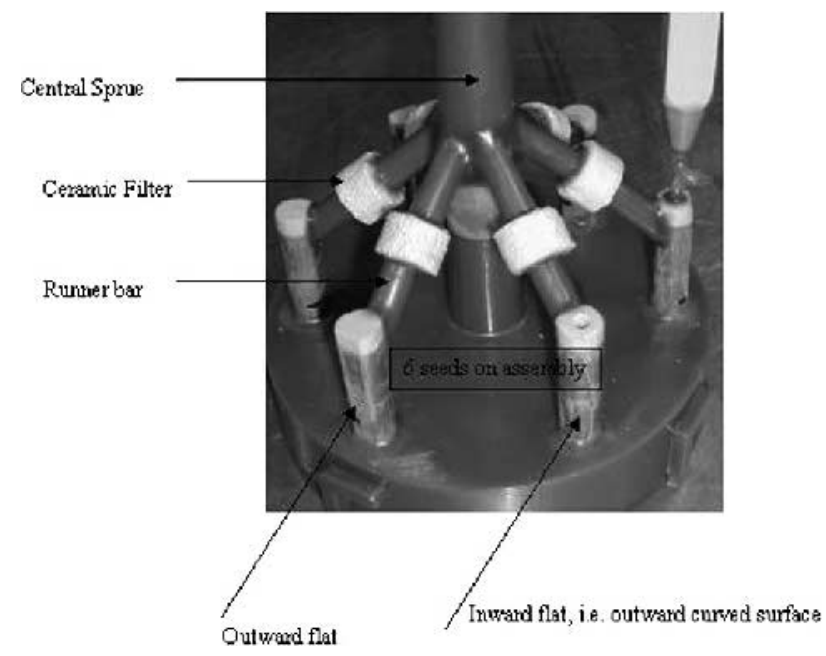

(b)

Fig. 2-(a) Schematic diagram of the furnace and $(b)$ photo illustrating inward- and outward-facing seeds.

desired orientation is raised into the furnace. The seeds are contained in the mold and rest on the water-cooled copper chill plate, which is fitted to the ram. 
(2) The mold is subsequently left for a period of time $(\approx 20$ minutes) to soak. During soaking, a partial melt-back of the seed takes place, depending on the soak temperature.

(3) Following the soak, the charge in the upper melting chamber is induction melted and poured into the mold cavity. The ram containing the mold is then withdrawn from the furnace at a predetermined speed. The withdrawal rate in the present experiments was $1 \times 10^{-4} \mathrm{~ms}^{-1}$. Thermocouple measurements yielded an average thermal gradient of $3 \mathrm{Kmm}^{-1}$, and details are reported elsewhere. ${ }^{[8]}$

In all the casting experiments, the alloy used was the second-generation superalloy CMSX4. The nominal composition and liquidus temperature (measured using differential thermal analysis) are given in Table $\mathrm{I}^{[8]}$

\section{B. Experiments for Investigating the Chill Effect of the Mold Wall}

In order to eliminate any chilling effect associated with a cold mold, three different soak temperatures were used with a standard soak time, and the corresponding melt-back from the base of the seed was measured in each case. This was done using routine optical microscopy on longitudinal seed sections. The sections were initially ground flat using a grind-stone of 150 grit, followed by a polishing with $9 \mu \mathrm{m}$ and then $3 \mu \mathrm{m}$ diamond slurries. These sections were subsequently etched with nimonic reagent to reveal the dendritic structure. The soak conditions used led to mold temperatures of $1475{ }^{\circ} \mathrm{C}, 1500{ }^{\circ} \mathrm{C}$, and $1525^{\circ} \mathrm{C}$, with a soak time of 20 minutes. In order to determine the role of the superheating of the liquid-melt charge in relation to the soak conditions in producing an additional melt-back in the seed (Point 2 in Section II-A), in each mold cluster, runners feeding alternate seeds on the carousel were plugged to block the introduction of liquid metal. Therefore, the flow of superheated liquid only occurred across the seed surface for three of the six seeds in each assembly. Referring to Table II, the seeds not experiencing superheated liquid metal across their surface are classified as dummy seeds. The seeds were

Table I. Nominal Composition (Weight Percent) of CMSX4 and Liquidus Temperature

\begin{tabular}{ccccccccccc}
\hline $\mathrm{Cr}$ & $\mathrm{Co}$ & $\mathrm{Mo}$ & $\mathrm{W}$ & $\mathrm{Ta}$ & $\mathrm{Re}$ & $\mathrm{Al}$ & $\mathrm{Ti}$ & $\mathrm{Hf}$ & $\mathrm{Ni}$ & $T_{\mathrm{Liq}},{ }^{\circ} \mathrm{C}$ \\
\hline 6.5 & 9.0 & 0.6 & 6.0 & 6.5 & 3.0 & 5.6 & 1.0 & 0.1 & bal & 1385 \\
\hline
\end{tabular}

Table II. Preliminary Experiments Related to Seed MeltBack for Given Soak Conditions

\begin{tabular}{lccc}
\hline Alloy Charge & $\begin{array}{c}\text { Mold Soak } \\
\text { Temperature }{ }^{\circ} \mathrm{C}\end{array}$ & $\begin{array}{c}\text { Melt-Back } \\
\text { Initiation from } \\
\text { Base }(\mathrm{mm})\end{array}$ & $\begin{array}{c}\text { Number of } \\
\text { Experiments }\end{array}$ \\
\hline CMSX4/none & 1475 & $\begin{array}{c}\text { cast }=20 / \\
\text { dummy }=26\end{array}$ & $\begin{array}{c}3 \text { cast/ } \\
3 \text { dummy }\end{array}$ \\
CMSX4/none & 1500 & $\begin{array}{c}\text { cast }=17 / \\
\text { dummy }=18 \\
\text { cast }=14 / \\
\text { dummy }=13\end{array}$ & $\begin{array}{c}3 \text { dummy } \\
3 \text { cast/ } \\
3 \text { dummy }\end{array}$ \\
CMSX4/none & 1525 & \begin{tabular}{c} 
dummy \\
\hline
\end{tabular}
\end{tabular}

in the as-cast state and shaped in the form of truncated cylinders (diameter $=12 \mathrm{~mm}$ and height $=35 \mathrm{~mm}$ ) with a longitudinal flat of width of $9 \mathrm{~mm}$. Unless otherwise stated, the seeds were located in the mold such that the reference flats faced radially outward toward the heater, i.e., away from the central sprue (Figure 2). The seeds had off-axial orientations, with the primary $<001>$ deviating from the vertical $(Z)$ axis in the range of 13 to $18 \mathrm{deg}$.

For the case of the soak temperatures of $1500{ }^{\circ} \mathrm{C}$ and $1525^{\circ} \mathrm{C}$, the overlying melt temperature was approximately the same as the mold soak temperature. Therefore, in all the subsequent experiments, the soak conditions adopted were $1500{ }^{\circ} \mathrm{C}$ and a soak time of 20 minutes.

\section{Experiments Related to Growth of Stray Grains}

In this section, we consider the competitive growth between the stray grains nucleated at the perimeter of the seed and the seed crystal. There are two quite distinct sources of asymmetry in the growth of single crystals. First, since the castings consist of clusters of specimens around a central sprue, the heat-transfer conditions toward the sprue and toward the furnace will be different, leading to a possible inclination, or curvature, of the solid-liquid interface; this will apply to both symmetric $<001>$ and off-axis orientations. Second, for off-axis orientations, the inclination of the dendrites with respect to the geometry of the casting may affect the mechanisms of competitive grain growth between the seed and any stray grains nucleated at the periphery. Here, we report a series of experiments intended to differentiate the roles of (1) specimen disposition in the asymmetric furnace conditions and (2) the inclination of the dendritic structure relative to the casting geometry on the nucleation and competitive grain growth of stray grains.

Figure 3 shows a typical single-crystal casting; the seed and initial part of the single-crystal growth before the spiral selector is encountered, which are cylindrical, were carefully characterized in the present study. An orthogonal co-ordinate system was defined with the $Z$-axis along the cylinder axis and the $X$-axis normal to either a reference longitudinal flat or an inscribed line on the casting surface (see Figure 3(a)). The dominant dendrite-growth direction, along the $<001>$ direction closest to the $Z$-axis, can be defined by the two angles $\theta$ and $\omega$, where $\theta$ is the angle between the dendrite axis and the $Z$-axis of the casting and $\omega$ is the azimuthal angle between the plane normal to the $Y$-axis and the plane containing the dendrite and the $Z$-axis of the casting.

For each casting, the position of stray grains around the perimeter was related to the specimen frame of reference. The segment of the perimeter containing stray grains which propagate upwards beyond $\sim 2 \mathrm{~mm}$, such as in Figure 1(b,) was defined by the two angles $\beta_{1}$ and $\beta_{2}$, measured from the $X$-axis in an anticlockwise direction (Figure 3(b) and (c)).

The relationship of the dendrite direction to the specimen frame of reference allows the segment of the casting perimeter where dendrites diverged on growth from the mold to be defined. This will consist of a semicircle with limits of $\pm 90 \mathrm{deg}$ from the projection of the dendrite direction on the $X Y$ specimen plane. These angles are designated as $\alpha_{1}$ and $\alpha_{2}$, respectively.

Of the two halves of the cylinder cross section, in the lefthand half, the primary $<001>$ stems at the seed perimeter 


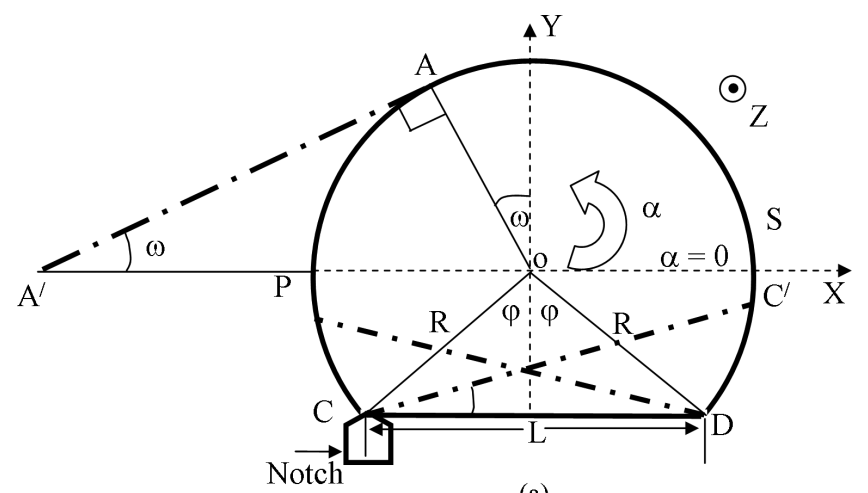

(a)

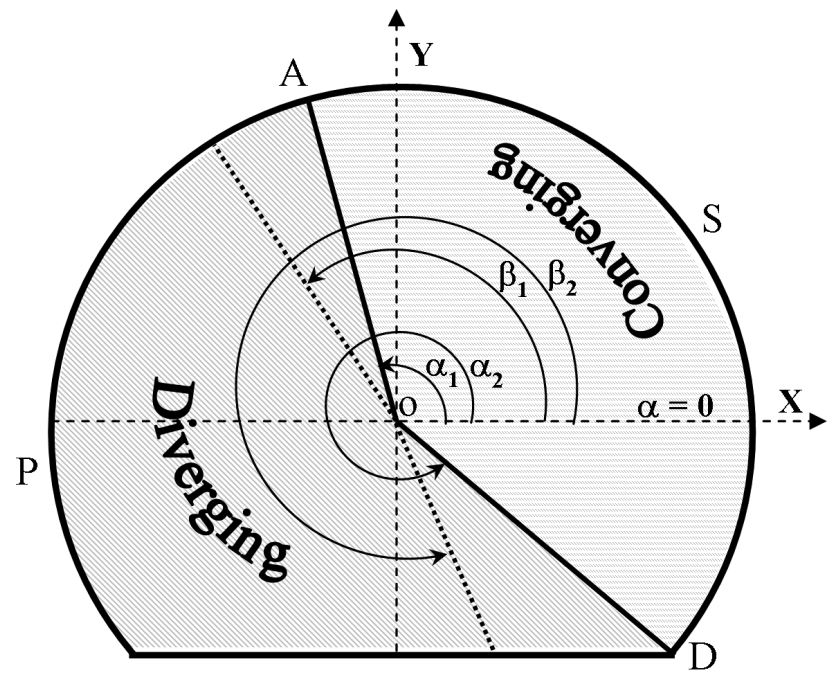

(b)

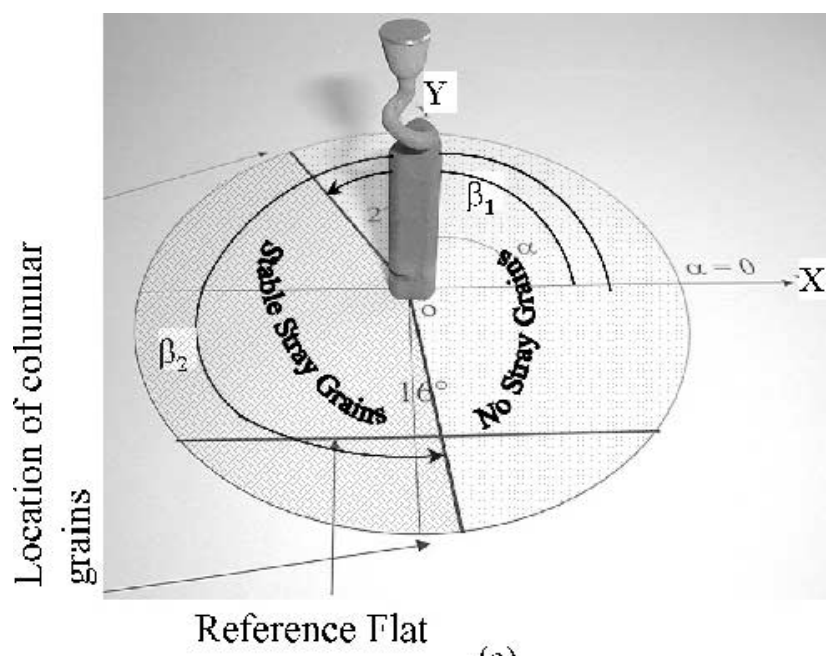

(c)

Fig. 3-(a) Schematic diagram to describe the definition of the crystallographic orientation of the seed. $(b)$ Definition of angles and regions where $<001>$ primary dendrites meet the mold wall in a converging and diverging fashion. (c) Three-dimensional image showing how $\beta_{1}$ and $\beta_{2}$ demark the region where stable stray grains form.

have a diverging disposition with respect to the mold wall, while in the right-hand half, they have a converging disposition.

When the seed has a reference flat (CD) of width $L$, that is parallel to, but displaced from, the $X$-axis, then $L=2 R$ $\sin \varphi$, where $R$ is the cylinder radius and $\varphi$ is half the angle subtended by the flat at the specimen axis. In the present experiments, $\varphi=48.6 \mathrm{deg}, R=6 \mathrm{~mm}$, and $L=9 \mathrm{~mm}$. For this truncated cylindrical-seed geometry, depending on the seed-flat location, i.e., the magnitudes of $\varphi$ and $\omega$, there are two possible cases that could affect the values of $\alpha$ where stray grains might be observed: (1) $\omega \leq \varphi$ and (2) $\omega>\varphi$. For both cases, the primary $<001>$ stems at the seed perimeter form a diverging disposition in relation to the mold wall within the region APD and are converging over the remaining portion ASD (Figure 3(b)). The angles $\alpha_{1}$ and $\alpha_{2}$, defined in Figure 3(b), have the following characteristics:

(1) For $\omega \leq \varphi$ : $\alpha_{1}=[90+\omega] \operatorname{deg}$ and $\alpha_{2}=[270+\varphi] \operatorname{deg}$

(2) For $\omega>\varphi$ : $\alpha_{1}=[90+\omega] \operatorname{deg}$ and $\alpha_{2}=[270+\omega] \operatorname{deg}$

Since the nucleation of stray grains has been observed to be fairly uniform across the seed perimeter, ${ }^{[2]}$ the focus of the present investigation has been to study the growth of these stray grains. Rather than attempt to count these spurious grains or report the extent (area fraction on transverse sections) to which they manage to grow into the primary seed crystal, we instead measure the spatial limits of stray columnar grains across the perimeter of the seed cross section through the angular limits $\beta_{1}$ and $\beta_{2}$, measured counterclockwise (Figures 3(b) and (c)). These angles $\left(\beta_{1}\right.$ and $\beta_{2}$ ) can then be compared to the angles $\left(\alpha_{1}\right.$ and $\left.\alpha_{2}\right)$ that define where the primary $<001>$ dendrites diverge or converge with the vertical mold wall.

\section{Effect of asymmetric thermal environment on stray-} grain development

The influence of the seed orientation with respect to the mold heater/central sprue on the formation of stray grains was investigated using both cylindrical and truncated cylindrical seeds. Experiments were carried out with the disposition of the off-axis specimens to the furnace geometry reversed, i.e.,

Case 1: Reference flat/line facing outward toward the heater

Case 2: Reference flat/line facing inward toward the central sprue

The results from 12 experiments, six each for cases 1 and 2, are listed in Table III. The experimentally measured angular ranges $\left(\beta_{1}\right.$ and $\left.\beta_{2}\right)$ within which the stray columnar grains were present on etched macrosections across the seed perimeter are tabulated, together with the calculated angular range $\left(\alpha_{1}\right.$ and $\left.\alpha_{2}\right)$ corresponding to the range of primary $<001>$ dendrites intersecting the mold wall at diverging angle. The correlation between $\alpha_{1} / \beta_{1}$ and $\alpha_{2} / \beta_{2}$ is shown graphically in Figure 4 , illustrating that these angles are directly related, with $\alpha_{1} / \beta_{1}$ falling above the $1: 1$ line and $\alpha_{2} / \beta_{2}$ falling below it.

There are four specific observations that follow immediately from the graphical representation in Figure 4 in conjunction with the examination of etched seed macrosections.

(1) The limits $\beta_{1}$ and $\beta_{2}$ are encompassed within the limits of the angles $\alpha_{1}$ and $\alpha_{2}$, i.e., $\beta_{1} \geq \alpha_{1}$ and $\beta_{2} \leq \alpha_{2}$.

(2) This implies that the stray columnar grains across the seed perimeter observed on etched macrosections are exclusively restricted to where the primary $<001>$ of the seed crystal forms a diverging disposition with respect to the vertical mold wall. 
Table III. Defect Mapping in Single-Crystal Seeds-Role of Liquidus Isotherm Curvature

\begin{tabular}{|c|c|c|c|c|c|c|}
\hline \multicolumn{7}{|c|}{ Inward-Facing Reference Line/Flat } \\
\hline $\begin{array}{l}\text { Seed } \\
\text { Identity }\end{array}$ & $\begin{array}{l}\text { Cross } \\
\text { Section }\end{array}$ & $\theta / \omega(\operatorname{Deg})$ & \multicolumn{2}{|c|}{$\begin{array}{c}\text { Range of }<001> \\
\text { Diverging from Mold } \\
\text { Wall: } \alpha_{1} \text { and } \alpha_{2}(\text { Deg) }\end{array}$} & \multicolumn{2}{|c|}{$\begin{array}{c}\text { Range of Stray-Grain } \\
\text { Occurrence: } \\
\beta_{1} \text { and } \beta_{2} \text { (Deg) }\end{array}$} \\
\hline $\mathrm{J}$ & cylinder- & $14.6 / 24.0$ & 114 & 294 & 120 & 285 \\
\hline $\mathrm{L}$ & reference line & $14.6 / 30.2$ & 120 & 300 & 140 & 290 \\
\hline S & & $15.3 / 26.3$ & 116 & 296 & 150 & 280 \\
\hline A & truncated cylinder- & $14.6 / 25.9$ & 116 & 318 & 160 & 285 \\
\hline $\mathrm{E}$ & reference flat & $15.7 / 28.9$ & 119 & 318 & 240 & 280 \\
\hline $\mathrm{H}$ & & $15.6 / 28.9$ & 119 & 318 & 180 & 240 \\
\hline \multicolumn{7}{|c|}{ Outward-Facing Reference Line/Flat } \\
\hline $\begin{array}{l}\text { Seed } \\
\text { Identity }\end{array}$ & $\begin{array}{c}\text { Location of } \\
\text { Reference Line }\end{array}$ & $\theta / \omega(\operatorname{Deg})$ & \multicolumn{2}{|c|}{$\begin{array}{c}\text { Range of }<001> \\
\text { Diverging from Mold } \\
\text { Wall: } \alpha_{1} \text { and } \alpha_{2}(\text { Deg) }\end{array}$} & \multicolumn{2}{|c|}{$\begin{array}{c}\text { Range of Stray-Grain } \\
\text { Occurrence: } \\
\beta_{1} \text { and } \beta_{2} \text { (Deg) }\end{array}$} \\
\hline$\overline{\mathrm{K}}$ & cylinder- & $14.8 / 36.0$ & 126 & 306 & 150 & 310 \\
\hline M & reference line & $14.2 / 33.8$ & 124 & 304 & 155 & 290 \\
\hline $\mathrm{N}$ & & $13.0 / 42.3$ & 132 & 312 & 130 & 320 \\
\hline $\mathrm{B}$ & truncated cylinder- & $15.2 / 26.7$ & 117 & 318 & 150 & 295 \\
\hline $\mathrm{D}$ & reference flat & $14.0 / 33.2$ & 123 & 318 & 195 & 290 \\
\hline $\mathrm{F}$ & & $13.7 / 28.6$ & 119 & 318 & 120 & 300 \\
\hline
\end{tabular}

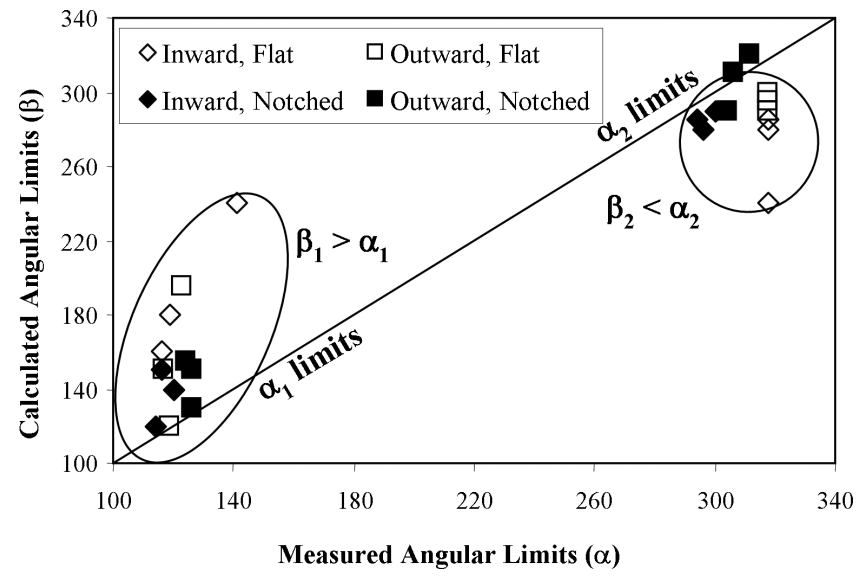

Fig. 4 - Comparison of the measured $\left(\beta_{1}\right.$ and $\left.\beta_{2}\right)$ and calculated $\left(\alpha_{1}\right.$ and $\left.\alpha_{2}\right)$ angular values for defect mapping in two seed types (cylinders with notches or flats) and two casting orientations (with the notch/flat facing inward or outward).

(3) The growth potential of the stray columnar grains is independent of the nature and orientation of the seed cross section with respect to the heater/central sprue.

(4) The occurrence of equiaxed grains is not biased toward any portion of the seed perimeter, i.e., they are not restricted to either the converging or diverging corner.

The results in Table III and Figure 4 indicate that the angular distribution of the stray columnar grains occurs in a region where the primary $<001>$ dendrites in the seed crystal are diverging from the cylindrical mold wall, regardless of seed cross section. Hence, the angular region associated with the columnar stray grains across the seed perimeter is invariant with respect to the inclination (diverging) of the seed primary $<001>$ stem with respect to the mold wall. It is concluded that any inclination or curvature of the liquidus isotherm due to specimen or furnace configuration has not significantly influenced the development of stray grains.

\section{Effect of primary dendrite orientation-axial/ converging/diverging}

The rotation of the seeds on the assembly alters the sense of the inclination of the primary stem in relation to the mold wall. In the case of the cylindrical seeds with an axisymmetric cross section, a rotation of the seeds on the assembly retains an invariant cross section with respect to the sprue/heater. This is, however, equivalent to a $180-$ deg rotation of the seed configuration (including the reference axes) and an accompanying rotation of $180 \mathrm{deg}$ in the viewing direction. The sense of the angles still remains the same. However, in the case of the truncated cylindrical seeds, the spatial orientation of the seed cross section in relation to the sprue/heater changes after a similar rotation.

It follows, therefore, from the results of Table III and Figure 4 , that the sense of inclination of the $<001>$ primary dendrite stem in relation to the vertical mold wall has a significant contribution to the competitive growth of stray nucleated crystals at the mold wall. To explore the role of the inclination of the $<001>$ primary dendrite stem further, similar experiments were conducted on cylindrical seeds having axial orientations within $\approx 2 \mathrm{deg}$ from $<001>$. Figure 5 represents typical views of the macro-etched section of a $<001>$ axially oriented seed across its cross section. As mentioned before, there was no measurement of $\omega$, since the seeds had an $\approx<001>$ axial orientation.

The following can be deduced from a comparison of Table III and Figure 5.

(1) Unlike the off-axial case, where the stray columnar grains were restricted to the diverging $<001>$ corner of the mold wall, for the case of the axial $<001>$ primary seed orientations, the columnar grains occur uniformly across the seed perimeter over a shorter distance.

(2) The equiaxed grains, as before, were not biased toward any portion of the seed perimeter. 

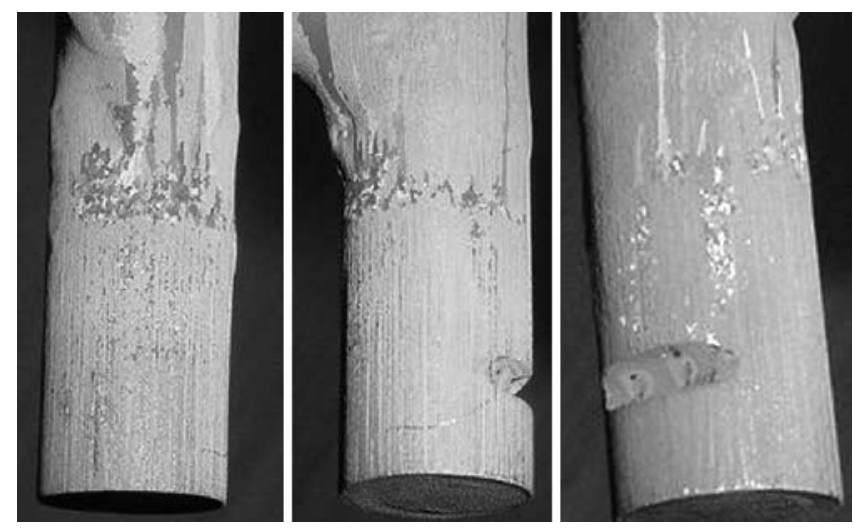

Fig. 5-Typical views of the macro-etched surface of the melt-back seed, indicating the distribution of equiaxed grains.

\section{MODELING INVESTIGATION}

A microscale cellular-automaton-finite-difference (CA-FD) model was used to simulate the dendritic growth and heterogeneous nucleation during seed melt-back. The model solves for the solute diffusion-controlled growth of cubic structured alloys, predicting the growth of the columnar dendrites from the seed and their competitive growth interactions with stochastically nucleated stray grains. The stochastic nucleation is based on the undercooling of the melt locally relative to that location's liquidus temperature, accounting for any solute enrichment at that location. The theory, implementation, and validation of this model are detailed in prior publication $\mathrm{s}^{[9-14]}$ and are not repeated here.

In this section, the simulation parameters used in this study are first described, and then the model is applied to the prediction of the microstructures as a function of the seed orientation relative to the wall. Although the model is three-dimensional, only two-dimensional results are presented here, since they are sufficient to elucidate the influence of the orientation of the seed to the wall as one moves around the periphery of the seed (i.e., from a converging to diverging misorientation).

\section{A. Simulation Parameters}

The domain size used in all simulations was $3 \times 6 \mathrm{~mm}^{2}$, sufficient to approximate the area near the mold wall where stray grains were observed experimentally. In each case, an initial fixed spacing of the dendrites in the seed of $350 \mu \mathrm{m}$ was used; however, their orientation relative to the isotherms was varied.

A pseudobinary approximation of CMSX4 was used in the simulation. The equilibrium data were obtained from a linearized phase diagram for a binary system. The partitioning coefficient $(k)$, diffusion coefficients $(D)$, and slope of the liquidus $(m)$ were assumed to be constant. The binary Ni-Ta phase diagram (initial concentration $C_{0}=6.5 \mathrm{wt}$ pct, $m=$ -4.74 , and $k=0.70$ ) has been used to describe the solidification characteristics of the superalloy CMSX4. This has been considered appropriate, since (1) the value of $k$ in the binary system is similar to the partitioning of Ta in CMSX4, as reported elsewhere, ${ }^{[15]}$ and (2) the solidification characteristics will be controlled by the heavy refractory additions, which have sluggish diffusion coefficients $\left(D_{\mathrm{L}} \approx 10^{-9} \mathrm{~m}^{2} \mathrm{~s}^{-1}\right){ }^{[16]}$

A zero-flux boundary condition was applied to the leftand right-hand sides of the domain. Simulations were run

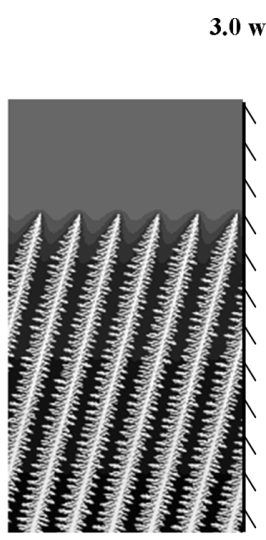

(a) (b)

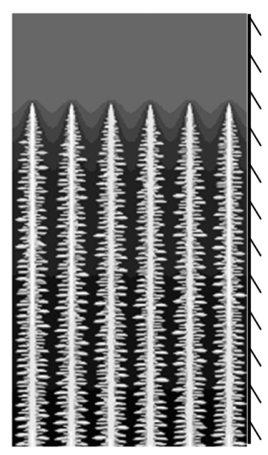

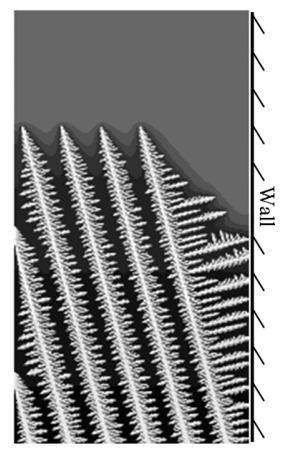

(c)
Fig. 6-Predicted microstructures for different dendrite orientations during seed melt-back under flat isothermal conditions: (a) converging, $(b)$ axial, and $(c)$ diverging.

for a pulling velocity of $100 \mu \mathrm{m} / \mathrm{s}$ and a thermal gradient of $3 \mathrm{~K} / \mathrm{mm}$. Either flat isotherms or curved thermal fields were imposed upon the domain to simulate the thermal conditions experienced during the melt-back process.

Heterogeneous nucleation was implemented in the CAFD mode ${ }^{[14]}$ during the seed melt-back. Nucleation in liquid occurs when its local undercooling $\left(\Delta T_{C}\right)$ exceeds the critical nucleation undercooling $\left(\Delta T_{N}\right)$. The propensity for stray-grain nucleation requires, therefore, a reliable measure of $\left(\Delta T_{\mathrm{N}}\right)$. Correlation of experimentally observed stray grains nucleated at the platform region with the calculated thermal undercooling indicates that $\Delta T_{N} \approx(10$ to 20$) \mathrm{K} \cdot .^{[17,18]}$ It must also be borne in mind that nucleation is a stochastic event. A Gaussian distribution was applied for nucleation in this simulation. In the absence of an accurate quantitative estimate for $\Delta T_{N}$ in CMSX4, the critical nucleation undercooling was assumed to be 12.3 , with a standard deviation of $\pm 0.4 \mathrm{~K}$ and with a nuclei density of $6.5 \mathrm{e}^{12} \mathrm{~m}^{-3}$.

\section{B. Predicted Undercooling and Microstructure During Seed Melt-Back}

Simulations were carried out to investigate the effect of the thermal profile and orientation of primary dendrites on the formation and growth of grains during seed melt-back. In this section, simulated dendritic structures and the amounts of undercooling predicted are presented under various thermal profiles (level and transient isotherms) and different orientations of the primary dendrites ( 0 and $\pm 15 \mathrm{deg})$.

\section{Structure evolution and undercooling under flat isotherms}

Flat isotherms are observed for both seeds of small diameter $(<6 \mathrm{~mm})^{[4]}$ and near the center of the seed during meltback. Simulations were, therefore, carried out under these conditions to examine casting characteristics in relation to stray-grain formation.

Figure 6 shows the evolution of the columnar dendrites growing upward from the bottom of the domain with the orientations of 0 and $\pm 15 \mathrm{deg}$, relative to the mold wall on the right-hand side. Since flat isotherms were applied in the simulation, level columnar fronts were observed. Figure 7 shows the microstructure in Figure 6 shaded by local 
undercooling rather than composition, where the undercooling was determined using the temperature- and compositionadjusted liquidus of each liquid and growing cell.

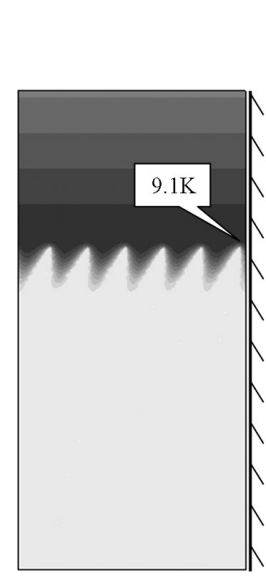

(a)
0

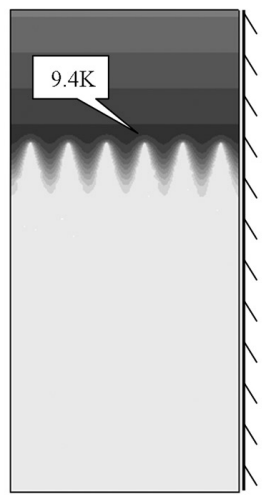

(b)

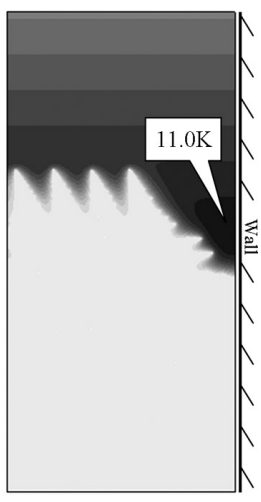

(c)
Fig. 7-Predicted undercoolings for different dendrite orientations during seed melt-back under flat isothermal conditions: $(a)$ converging, $(b)$ axial, and $(c)$ diverging (corresponding to the microstructures in Fig. 8).

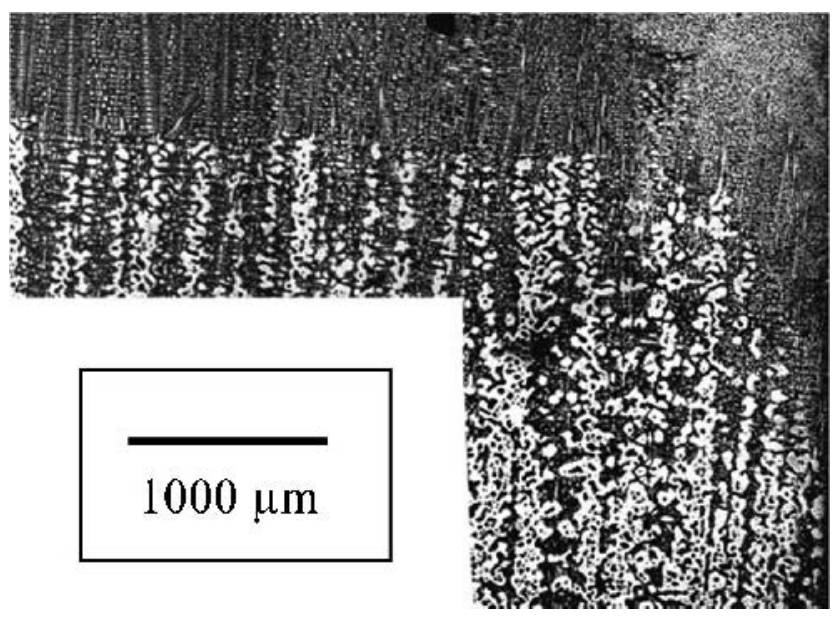

Fig. 8-Longitudinal optical micrograph to reveal the convex-up shape of the interface during seed melt-back (based on Ref. 4).
The following observations were made.

(1) Converging: The primary dendrites were terminated when they reached the wall. The maximum undercooling near the wall was $9.1 \mathrm{~K}$.

(2) Axial: All primary dendrites grew at the same rate and had a similar undercooling profile. Their tip undercooling was $9.4 \mathrm{~K}$.

(3) Diverging: An increasing volume of liquid was formed between the mold wall and the diverging primary dendrites during growth. A maximum undercooling of $11.0 \mathrm{~K}$ was predicted at the evolving gap, while it was $9.6 \mathrm{~K}$ at the center. If the undercooling was lower than the critical nucleation undercooling, secondary and tertiary arms developed to fill up the open body of liquid. Otherwise, nucleation occurred.

Although the absolute value of these predicted undercoolings depends on estimated model-input parameters, the overall trend that the undercooling is highest for diverging seed dendrite orientations holds.

\section{Structure evolution and undercooling during the initial thermal transient}

Despite nominal solidification conditions (flat isotherms) existing within the seed, a rapid change in the local columnarfront curvature has been observed during the initial transient stages of withdrawal. In fact, quenched directional solidification studies on melted-back seeds in a Bridgman apparatus show a distinct, convex, upward curvature during the soak $^{[4]}$ (Figure 8). The shape of the isotherms can be estimated from the quenched solid/liquid interface at the mold wall during the initial withdrawal stage. The schematic diagram in Figure 9(a) shows the initial profile at melt-back that corresponds to Figure 8. During the initial withdrawal stage, the heat-transfer mode changes from chill conduction to mold-wall radiation, as experimentally observed by D'Souza et al. for a similar geometry in a Bridgman apparatus $^{[19]}$ (Figure 9(b)). Therefore, a transient thermal field was imposed upon the domain to simulate the initial stage following melt-back.

The transient thermal profile and the undercooling ahead of the dendritic tip for axial columnar dendrites are shown in Figure 10, with isotherms changing from a convex to concave shape. The maximum undercooling near the mold wall

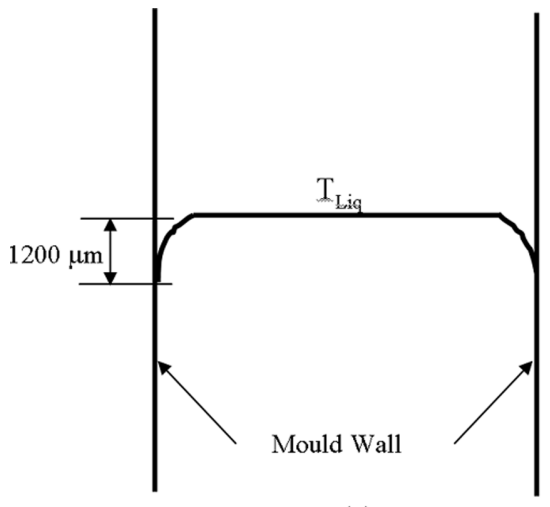

(a)

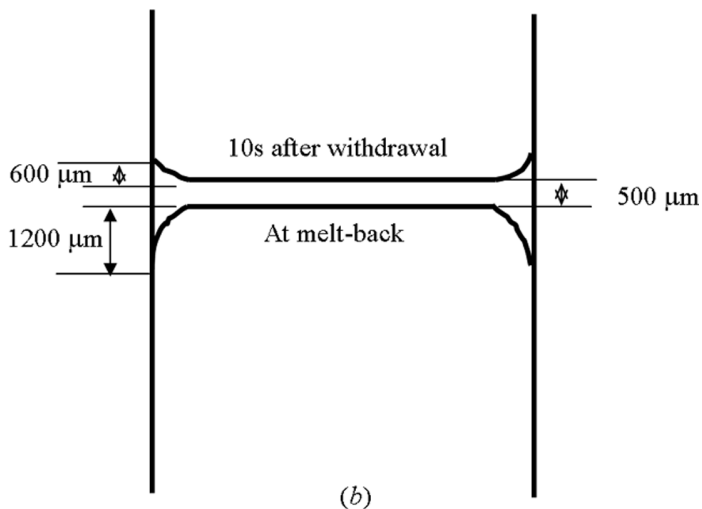

(b)

Fig. 9-Schematic diagram showing the transient thermal profile at the initial withdrawal during the seed melt-back process: $(a)$ convex-up shape of isotherms due to the conduction of heat through the bottom chill and $(b)$ convex shape due to the change of heat-transfer mode from chill conduction to mold radiation. 
0

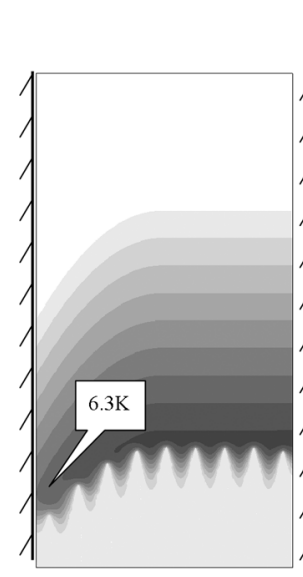

(a)
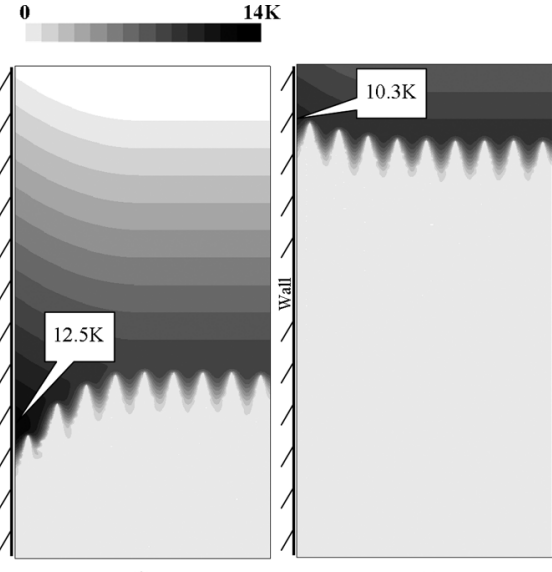

(b)

Fig. 10-Predicted undercooling for an axial dendrite during the initial thermal transient stage of seed melt-back, showing that the maximum undercooling occurs at the end of the transient: (a) $t=30 \mathrm{~s}$, (b) $t=40 \mathrm{~s}$ (corresponding to $12.5 \mathrm{~K})$, and $(c) t=70 \mathrm{~s}$.

was $6.3 \mathrm{~K}$ before the withdrawal, increasing to $12.5 \mathrm{~K}$ when the isotherms changed from convex to concave shapes due to the higher growth velocity and decreasing to $10.3 \mathrm{~K}$ after the columnar dendrites grew into steady state.

The simulated structures for different columnar dendritic orientations including heterogeneous nucleation are given in Figure 11. The maximum undercoolings corresponding to the different orientations with no nucleation (Figure 11) are given in Figure 12. The following observations can be made.

(1) Converging: The primary dendrites near the mold wall were terminated when they reached the wall. The undercooling ahead of the columnar dendrites in the center was the same as the results under level isothermals. However, the maximum undercooling near the wall was increased to $11.8 \mathrm{~K}$, compared with a general undercooling of $9.1 \mathrm{~K}$. New grains nucleated near the mold wall due to the higher undercooling and were overgrown by the growing columnar dendrites.

(2) Axial: The undercooling near the mold wall increased to $12.5 \mathrm{~K}$ compared with the level isotherms. This is because columnar dendrites near the mold wall grew at a higher rate during the transient stage than those under level isotherms, resulting in a higher undercooling. New grains formed during the transient stage and were overgrown by the columnar dendrites after the transient stage.

(3) Diverging: There is an increasing volume of liquid left between the mold wall and the diverging primary dendrites during growth. A maximum undercooling of $13.6 \mathrm{~K}$ was maintained at the evolving gap, while the undercooling at the center was $9.2 \mathrm{~K}$. Nucleation occurred near the diverging side, as shown in Figure 11(c). The nucleated grains grew to fill the gap between the mold wall and the columnar dendrites. Due to the open space of the gap left, the stray grains are not likely to be blocked by the original dendrites; therefore, they could grow into the single-crystal matrix to form columnar grains, as observed experimentally $^{[4]}$ (Figure 1(b)).

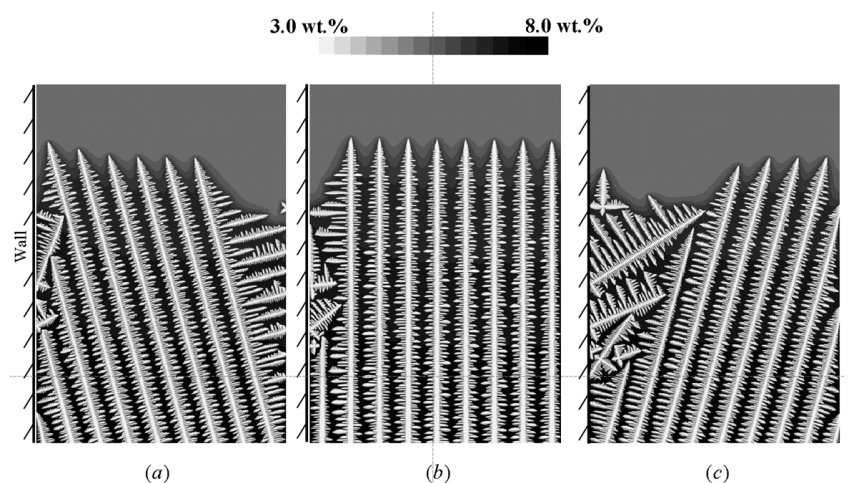

Fig. 11-Predicted microstructures with heterogeneous nucleation for different dendrite orientations during seed melt-back under transient thermal conditions: (a) converging, $(b)$ axial, and (c) diverging.
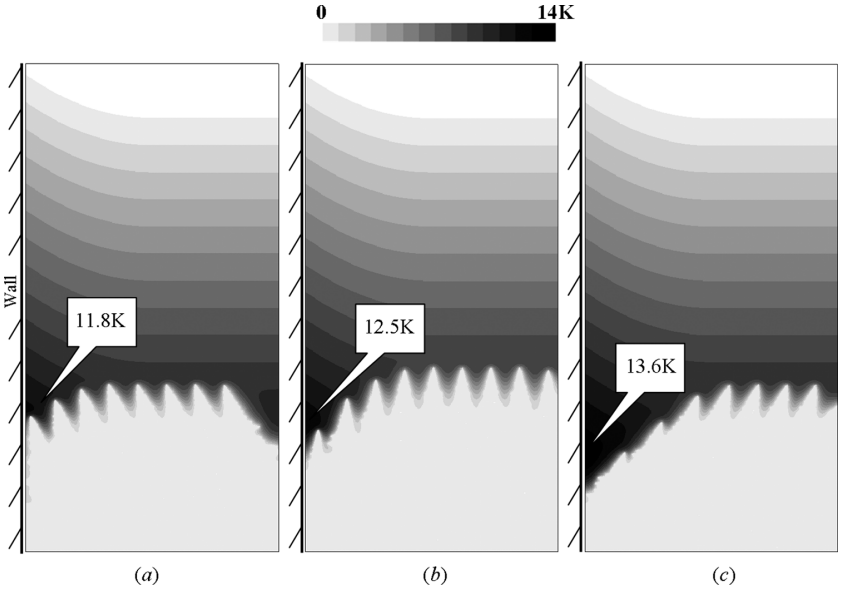

Fig. 12-Predicted maximum undercoolings for different dendrite orientations during seed melt-back under transient thermal conditions, showing that the maximum undercooling occurs at diverging grooves: $(a)$ converging, $(b)$ axial, and $(c)$ diverging (corresponding to $13.6 \mathrm{~K}$ ).

The simulated results revealed the following.

(1) The undercooling near the mold wall during the thermal transient stage is greater than the undercooling under level isotherms, while the undercooling ahead of the columnar front in the center of the domain is the same as that calculated under level isotherms.

(2) During the thermal transient stage, the undercooling reaches its maximum at the end of the transient stage, so the propensity for forming new grains during the thermal transient stage is high.

(3) For dendrites with different orientations, the diverging case has the highest undercooling $(13.6 \mathrm{~K})$. Therefore, the diverging groove provides a favorite location for nucleation and growth of stray grains.

\section{DISCUSSION}

\section{A. Nucleation of Stray Grains during Seed Melt-Back}

For nominal solidification conditions (flat isotherm, as described in Section III-A), the magnitude of $\Delta T_{C}$ ahead of the columnar front may be insufficient to cause nucleation 
of stray grains, despite the existence of a large volume of supercooled liquid. However, in the transient stage, the local solidification conditions experienced by the dendrites near the mold wall are very different than those encountered by the primary stems in the center. During the transient period, the curvature of the columnar front changes from a convex to concave shape. With regard to the increased isotherm velocity pertaining to rapid changes in growth-front curvature, there are four important features that need to be considered:

(1) The maximum undercooling occurred at the end of the initial transient stage near the mold wall (Figure 9(b)). For axial dendrites, the undercooling near the mold wall was $6.3 \mathrm{~K}$ before the initial withdrawal, increased to $12.5 \mathrm{~K}$ at the end of the transient stage, and decreased to $10.3 \mathrm{~K}$ when the columnar dendrites near the wall grew at the same rate as those in the center.

(2) The maximum undercooling was predicted for diverging dendrites. Predicted maximum undercoolings at the end of the transient stage for the converging $(\theta=-15 \mathrm{deg})$, axial $(\theta=0 \mathrm{deg})$, and diverging $(\theta=+15 \mathrm{deg})$ dendrites were $11.8,12.5$, and $13.6 \mathrm{~K}$, respectively. The undercoolings near the casting center for all dendrite orientations had a similar value of $9.1 \mathrm{~K}$.

(3) Undercoolings near the mold wall are greater than those at the center; therefore, the propensity of nucleation near the mold wall is greater than at the center.

(4) The previous simulations agree with experimental observations that the nucleation of stray equiaxed grains around the perimeter of the seed (Figure 1(a)) occurs within a distance of $\approx 2 \mathrm{~mm}$ from the melt-back interface and that the stray equiaxed grains do not have an angular dependency.

\section{B. Growth of Stray Grains}

The evolution of the stray grains is determined by their growth after nucleation, which is dominated by competitive growth with the original dendrites. In this section, the impact of primary dendrite orientation on the growth of stray grains is discussed. There are two distinct categories that deal with competitive grain growth based on the orientation of the dendrites.

(1) Converging: During the thermal transient stage, the existence of high undercooling provides a favorable condition for nucleation. However, during subsequent growth, the evolving primary/secondary dendrite-arm network of the columnar dendrites causes a reduced local undercooling in the volume of liquid available for the growth of the stray grain. The space available for the growth of the stray grains also diminishes as the original dendrites grow into the liquid, inhibiting growth of the nucleated grains.

(2) Diverging: A bulk of undercooled liquid exists due to a decreased solutal interaction between primary/secondary arms at the diverging groove. Moreover, the highly undercooled region of liquid is retained due to the lag of the growth front, which provides a favored condition for the growth of spurious grains. The nucleated grain in the diverging groove has a larger size than those at the axial and converging sides and has the potential to grow into the single-crystal matrix. This, therefore, accounts for the angular dependence of the occurrence of the stray columnar grains across the seed perimeter.

\section{CONCLUSIONS}

An experimental study along with a microstructural model treating solute diffusion has been used to address (1) the nucleation of stray grains following seed melt-back and the initial withdrawal and (2) the effect of the primary dendrite disposition of the seed with respect to the mold wall on the growth of stray crystals. The following conclusions were reached.

1. The local thermal conditions at the growth front with respect to the mold heater have minimal influence.

2. The maximum undercooling is obtained at the end of the thermal transient stage.

3. For seeds with an axial orientation, the stray grains nucleated across the seed perimeter exhibit a random columnar morphology, showing the absence of an angular relationship.

4. For seeds with an off-axial orientation, the growth of nucleated grains is governed by the morphological constraints associated with competitive growth between the nucleated grains and columnar dendrites. At the converging side, the nucleated grains were overgrown by the columnar dendrites after the transient stage and remain equiaxed. At the diverging side, the nucleated grains can grow significantly into the single-crystal matrix and exhibit a columnar morphology.

\section{ACKNOWLEDGMENTS}

The authors from Imperial College London are thankful for the financial support provided by EPSRC (Grant No. GR/R78992).

\section{REFERENCES}

1. M. McLean: Directionally Solidified Materials for High Temperature Service, The Metals Society, London, 1983, pp. 161-63.

2. N. Stanford, A. Djakovic, B.A. Shollock, M. McLean, and N. D'Souza: Superalloys 2004, K.A. Green, ed., TMS, Warrendale, PA, 2004, pp. $515-24$.

3. J.P. Gu, C. Beckermann, and A.F. Giamei: Metall. Mater. Trans. A, 1997, vol. 28A, pp. 1533-42.

4. N. Stanford, A. Djakovic, B.A. Shollock, M. McLean, N. D'Souza, and P.A. Jennings: Scripta Mater., 2004, vol. 50, pp. 159-63.

5. S.M. Copley, A.F. Giamei, S.M. Johnson, and M.F. Hornbecker: Metall. Trans., 1970, vol. 1, pp. 2193-204.

6. M.J. Goulette, P.D. Spilling, and R.P. Arthey: Superalloys 1984, TMSAIME, Warrendale, PA, 1984, pp. 167-76.

7. G.J.S. Higginbotham: Mater. Sci. Technol., 1986, vol. 2, pp. 442-60.

8. N. D'Souza and P.A. Jennings: personal communication, Rolls-Royce plc, U.K., 2002.

9. P.D. Lee and J.D. Hunt: Acta Mater., 2001, vol. 49, pp. 1383-98.

10. R.C. Atwood and P.D. Lee: Metall. Mater. Trans. B, 2002, vol. 33B, pp. 209-21.

11. W. Wang, A. Kermanpur, P.D. Lee, and M. McLean: Int. J. Cast Met. Res., 2002, vol. 15, pp. 269-71.

12. W. Wang, P.D. Lee, and M. McLean: Acta Mater., 2003, vol. 51, pp. 2971-87.

13. P.D. Lee, A. Chirazi, R.C. Atwood, and W. Wang: Mater. Sci. Eng. A, 2004, vol. 365, pp. 57-65. 
14. X.L. Yang, H.B. Dong, W. Wang, and P.D. Lee: Mater. Sci. Eng. A, 2004, vol. 386, pp. 129-39.

15. A. Wagner, N. D'Souza, B.A. Shollock, and M. McLean: Proc. 2001 Int. Symp. on Liquid Metal Processing and Casting, A. Mitchell, ed., TMS, Warrendale, PA, 2001, pp. 301-13.

16. M.G. Ardakani, N. D'Souza, A. Wagner, B.A. Shollock, and M. McLean: Superalloys 2000, T.M. Pollock, R.D. Kissinger, R.R. Bowman, K.A. Green, M. McLean, G.B. Olson, and J.J. Schirra, eds., TMS, Warrendale, PA, 2000, pp. 219-28.
17. M. Meyer ter Vehn, D. Dedecke, U. Paul, and P.R. Sahm: Superalloys 1996, R.D. Kissinger, D.J. Deye, D.L. Anton, A.D. Cetel, M.V. Nathal, T.M. Pollock, and D.A. Woodford, eds., TMS, Warrendale, PA, 1996, pp. 471-79.

18. A. Mahal: Development and Implementation of an Integrated Approach to Single Crystal Casting Process Modelling in a Production Foundry, Rolls-Royce plc, 2004.

19. N. D'Souza, M.G. Ardakani, M. McLean, and B.A. Shollock: Metall. Mater. Trans. A, 2000, vol. 31A, pp. 2877-86. 